\title{
DETERMINING THE OPTIMAL FEE-TECHNICAL PROPOSAL COMBINATION IN TWO ENVELOPE FEE BIDDING
}

\author{
Professor Derek S. Drew, Connie W.K. Kwong and Patrick X.W. Zou \\ University of New South Wales \\ L.Y. Shen, The Hong Kong Polytechnic University
}

\section{INTRODUCTION}

Bid strategy modelling has traditionally been concerned with setting the mark up level to a value that is likely to provide the best pay off. Famous construction bid strategy models include those proposed by Friedman (1956), Gates (1961) and Carr (1982). More recently bid strategy modelling has expanded to encompass contracts awarded on a multi-criteria basis. For example, construction clients are increasingly calling for bids that require competing contractors to submit both bid price and contract time (Shen et al., 1999). In such cases contractors' bid prices and proposed contract times are commonly assessed in accordance with the following equation (Herbsman et al., 1995):

TCB $=p+($ UTV $x \mathrm{t})$

where

TCB $=$ Total combined bid

$\mathrm{p}=$ price

UTV = unit time value specified by the client (such as liquidated damages rate)

$\mathrm{t}=$ time

The contractor with the lowest TCB is awarded the contract. Shen et al. (1999) have considered this from a contractor's bid strategy viewpoint by relating the contractor's price-time curve to the client's pricetime curve and from this they have developed a mathematical bid optimisation model. The rationale behind the model is illustrated in Figure 1. It is widely accepted (e.g. Callahan et al., 1991) that every competing contractor has an optimum pricetime point for each construction contract. The price-time curve of a contractor is shown in Figure 1 as being $S_{1}$ with the optimum point as $B_{1}$ and the corresponding bid price-time combination as $p_{1}, t_{1}$. The liquidated damages rate, commonly used to represent UTV, is shown as a straight line $\left(\mathrm{S}_{2}\right)$ since it is a constant rate. The total combined bid curve $S$ (i.e. assessed cost to the client) becomes $S_{1}+S_{2}$. The optimum point at which the contractor is most competitive from the client's viewpoint is $\mathrm{B}_{0}$. The contractor should, therefore, submit the bid price-time combination $p_{a} t_{0}$ to the client.

Consultants are faced with a similar problem in two envelope fee bidding given that the commission is awarded on the combined basis of price (i.e. fee) and quality (i.e. technical proposal). Consultants are required to submit to the client one envelope containing the technical proposal and a second envelope containing the fee. Each competing consultant's technical proposal and fee is then converted by the client to a score and aggregated. The consultant with the highest overall score is then awarded the commission (see, for example, Construction Industry Board (1996) for a detailed explanation of two envelope fee bidding procedures).

Bid strategy decision making is more complicated in price-time contracts and two envelope fee bidding. In addition to setting the mark up level to provide the best pay off, bidders need to make an additional decision with regard to the second criterion. For example, they must decide whether to submit a higher (or lower) tender price with a shorter (or longer) contract period, or in the case of two envelope fee bidding, on whether to aim for a higher technical score (which is likely to require a higher fee) or submit a lower fee (which is likely to result in a lower technical score). The objective of an optimum bid strategy model is to provide the bidder with an optimal solution, whether it be optimum mark-up (as with traditional price only models) or optimum price-time or fee-technical score combination (with biparameter models). 
Figure 1: The price-time relationship between the contractor's price-time curve $\left(\mathrm{S}_{1}\right)$ and the client's price-time curve (S) (Source: Shen et al. 1999)

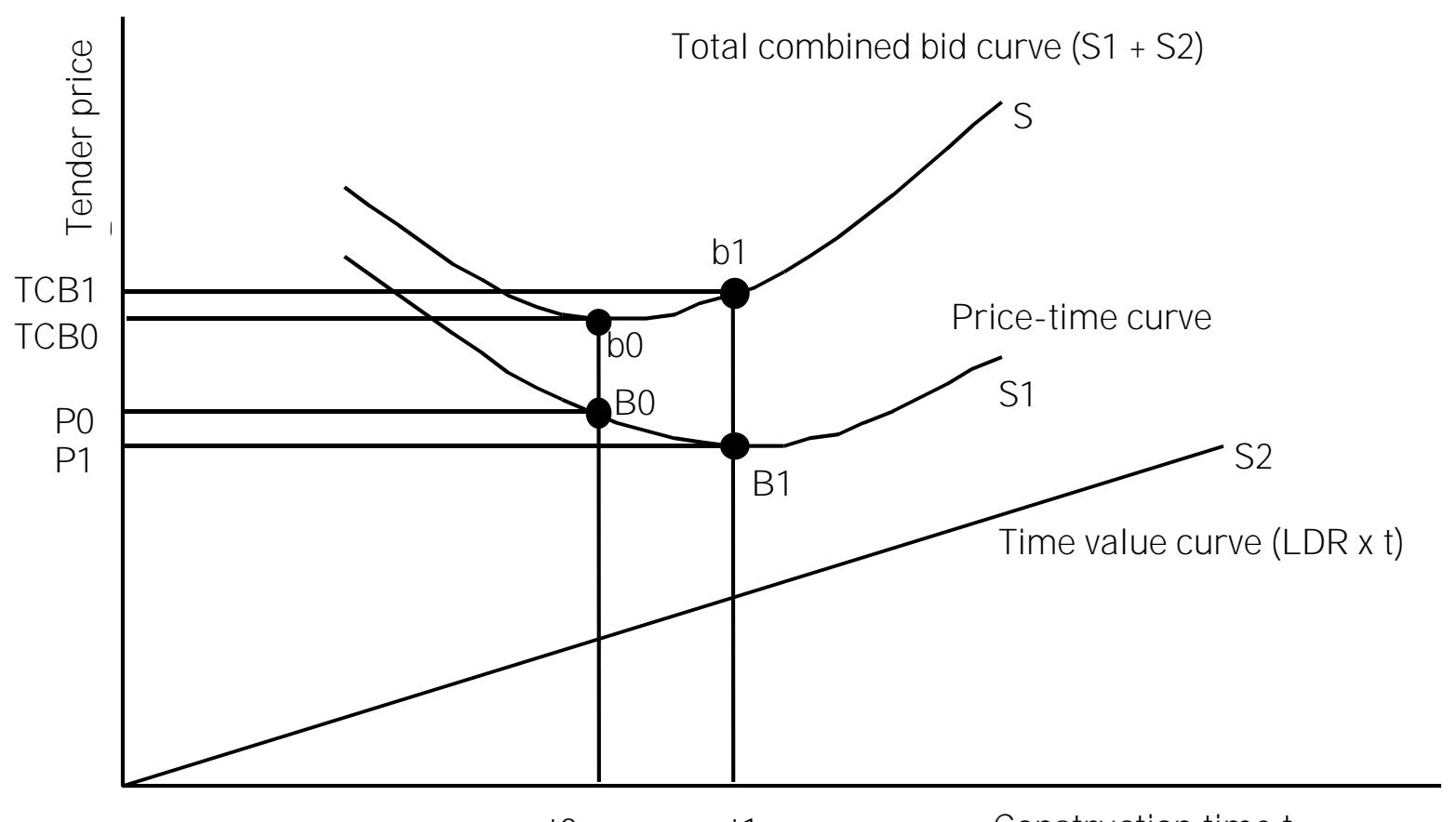

to

t1

Construction timet

Based on the same logic proposed by Shen et al. (1999), Drew et al. (2002b) offered consultants an optimum bid strategy model for two envelope fee bidding. They show that consultants have a choice of aiming for a low scored technical proposal-low fee combination or a high scored technical proposal-high fee combination or a combination in between, and that only one of these combinations will result in the highest possible aggregated score. They claim that if consultants follow the modelling approach set out in their paper, they should be in a position to better identify their optimum feetechnical score combination, thereby increasing their chances of winning the commission. Drew et al. (2002b) introduced the modelling approach using hypothetical examples. This paper sets out to test the modelling approach using data supplied by a Hong Kong quantity surveying consultant.

\section{Aggregating fees and technical score}

Construction clients set out the two envelope bidding procedures that consultants are required to follow. This includes using a particular formulation with which to aggregate the fees and technical scores. Drew et al. (2001) identified seven different feetechnical score formulations from the literature and also suggested two more new formulations. A commonly used formulation (Connaughton, 1994), also used by the Hong Kong Housing Authority (one of Hong Kong's largest public sector clients), is:

$$
\mathrm{C}_{\mathrm{A}}=\mathrm{W}_{\mathrm{q}} \mathrm{q} / \mathrm{q}_{\max }+\mathrm{W}_{\mathrm{f}} \mathrm{f}_{\text {min }} / \mathrm{f}
$$

where

$\begin{array}{lll}\mathrm{q}_{\max } & = & \text { highest technical score } \\ \mathrm{q} & = & \text { consultant's technical score } \\ \mathrm{f} & = & \text { consultant's fee } \\ \mathrm{f}_{\min } & = & \text { lowest fee } \\ \mathrm{W}_{\mathrm{q}} & = & \text { predetermined weighting } \\ & & \text { for technical score } \\ \mathrm{W}_{\mathrm{f}} & = & \text { predetermined weighting } \\ & & \text { for fees } \\ \mathrm{C}_{\mathrm{A}} & = & \text { total score }\end{array}$

The consultant with the highest $C_{A}$ value wins the contract. For example, suppose there were four competing consultants labelled A, B, C and D who submitted respective fees of $\$ 5.43, \$ 5.14, \$ 4.42$ and $\$ 4.62$ million and whose technical proposals were given scores of 82, 76, 69 and 73. Suppose also that the technical score/fee predetermined weightings were 70/30 respectively. Table 1 shows Consultant A winning the competition. 
Table 1: Aggregating fee and technical score using Equation 2

\begin{tabular}{|l|l|l|l|l|l|l|}
\hline $\begin{array}{l}\text { Consultant } \\
\text { Identities }\end{array}$ & TM & F\$M & TSC & FSC & TotSc & Rank \\
\hline A & 82 & 5.43 & 70.0 & 24.3 & 94.30 & 1 \\
\hline B & 76 & 5.14 & 65.1 & 25.8 & 90.90 & 3 \\
\hline C & 69 & 4.42 & 58.8 & 30.0 & 88.80 & 4 \\
\hline D & 73 & 4.62 & 62.3 & 28.7 & 91.00 & 2 \\
\hline
\end{tabular}

The example also shows that fees and technical scores are, to some extent, positively correlated (i.e. Consultant A submitted the highest fee and obtained the highest technical score, Consultant C submitted the lowest fee and obtained the lowest technical score and Consultants B and D somewhere in between). It can be seen that this becomes a negative correlation when converted to a ratio since the fee ratio is an inverse ratio. An important reason for such a correlation is that architectural, engineering and surveying commissions are regarded as a 'complex intellectual process' (Construction Industry Board, 1996) and as such, in order to deliver a good quality service, two important variables are total time spent on the commission, and experience of the consultant. With a lower fee the consultant will not be able to spend so much time on the commission and/or use less experienced staff. Spending less time and/or using less experienced staff should result in the consultant receiving a lower raw technical score. On the other hand, greater experience and more involvement are likely to result in a consultant receiving a higher technical score. Since experienced staff are normally paid higher salaries this is likely to require a larger fee. A higher technical score therefore requires a larger fee, and fees are likely to go up at an increasing rate according to the technical score (because of the increased rate of salary differences between lower and higher paid staff). This suggests that there is a positive convex correlation between fee and raw technical score.

The fee-raw technical score correlation that is often produced when consultants are in competition with one another will also occur with a particular consultant deciding on whether to aim for a low scored technical proposal-low fee combination or a high scored technical proposal-high fee combination or something in between. For example, suppose Consultant A had developed three technical proposals for the commission just described. The three technical proposals may attract full fees of say $\$ 4.43, \$ 5.43$ and $\$ 6.43$ million respectively. If all three technical proposals were scored it is quite likely that the raw technical scores and corresponding fees would, to some extent, be positively correlated.

\section{Determining the optimum fee and technical score}

The consultant's objective in two envelope fee bidding is to get the highest possible total score since this maximizes the chance of winning the commission. In the previous example the consultant would submit the fee-technical proposal combination that it thought would result in the highest score. Drew et al. (2002b) claim that consultants can actually determine the highest scoring fee-technical proposal combination for a particular commission by following the following seven steps:

1. Assemble the technical proposal and calculate the corresponding fee in the normal way, then estimate the corresponding technical score.

2. Determine the absolute lowest full fee for the commission and estimate the corresponding technical score

3. Estimate the absolute highest technical score for the commission and determine the corresponding full fee.

4. Use the client's formulation (e.g. Equation 2) and calculate the three respective total scores using (1) the original fee and corresponding technical score, (2) absolute lowest fee and corresponding technical score and (3) absolute highest technical score and corresponding fee. 
Figure 2: Possible optimum fee outcomes (Source: Drew et al. 2002b)

Case 36

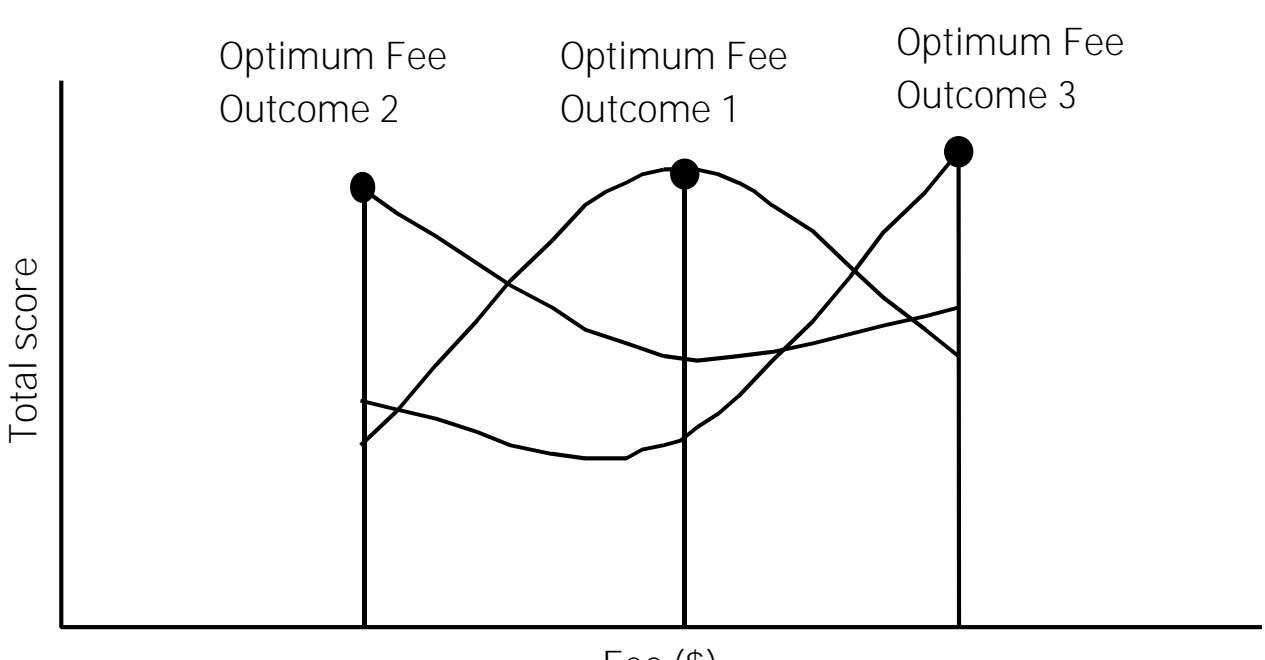

Fee $(\$)$

5. Regress the three total scores against the fee to produce a total score continuum. Since the continuum, represented by a line, is regressed on three points it will almost certainly be curvilinear in shape, being either concave or convex. Figure 2 shows that there are three possible outcomes. If concave, the optimum fee will fall at the highest point along the continuum (i.e. Outcome 1). If, however, the continuum is convex, the optimum fee will fall at either the low end (i.e. Outcome 2) or high end (i.e. Outcome 3) of the continuum.

6. Determine the optimum fee for Outcome 1 using differentiation since the total score continuum, represented by a curvilinear regression line, is based on the equation:

$Y=a+b x+c x^{2}$

where

$\mathrm{Y}=$ total score

$\mathrm{X}=$ fee

For Outcome 2 and 3 the optimum fee is simply that shown at either the low end (i.e. Outcome 2) or high end (i.e. Outcome 3 ) of the continuum.

7. Determine the optimum technical score for Outcome 1 by inserting the optimum fee and total score into the client's formulation to find the corresponding technical score. For Outcome 2 and 3 the optimum technical score is the one already estimated. The original technical proposal should then be adjusted to reflect the optimum technical score. This may involve including more/less staff with greater/less experience and/or spending more or less time on the commission. The optimum fee and the adjusted technical proposal should then be submitted to the procurer.

In addition to illustrating the foregoing approach using hypothetical examples, Drew et al. (2002b) were able to show the effect of using the optimum bid strategy on bidding performance. They identified that this could be done by measuring the optimum total score percentage increase on the original total score. This seven step approach will be replicated and developed in this paper using data collected from a leading Hong Kong quantity surveying consultant.

\section{DATA COLLECTION}

The consultant, who regularly tenders for Hong Kong Housing Authority commissions, provided the following data for 51 bidding attempts:

1. Original fee

2. Estimated raw score

3. Absolute low fee

4. Corresponding estimated technical score

5. Absolute high estimated technical score

6. Corresponding fee 
7. Fee/technical score predetermined weighting

8. Tender date

The commissions were tendered for between September 1997 and April 2001. The Hong Kong Housing Authority used feetechnical score predetermined weightings of 30/70 for 14 cases and 50/50 for the remaining 37 cases. The fees submitted ranged from just under $\mathrm{HK} \$ 1$ million to just under HK\$17 million. The Hong Kong Housing Authority uses Equation 2 to aggregate fees and technical scores.

\section{ANALYSIS}

The analysis is in three parts. Three representative cases are used in the first part of the analysis to illustrate each of the three possible outcomes (i.e. Outcome $1=$ in between absolute low fee/absolute high technical score, Outcome $\mathbf{2}$ = absolute low fee/low technical score, Outcome 3 =absolute high technical score/high fee). The frequency of the three possible outcomes and the effect of the predetermined weightings are considered in the second part of the analysis. The last part considers the effect that the optimum bidding strategy has on the consultant's original bidding performance.

\section{REPRESENTATIVE CASES ILLUSTRATINGTHE THREE DIFFERENTOUTCOMES}

The three possible outcomes are illustrated with cases 36, 37 and 38. Table 2 shows the (1) original fee/estimated raw score, (2) absolute low fee/corresponding estimated technical score and (3) absolute high estimated technical score/corresponding fee combinations for these three representative cases. The fees and technical marks are converted into fee, technical and total scores using Equation 2. For Case 36 it can be seen the consultant's original fee and estimated raw score produced the highest score, while for Case 37 the absolute high estimated technical score and corresponding fee resulted in the highest total score and for Case 38 the absolute lowest fee/corresponding technical score combination yielded the highest total score.

Regression analysis is used to produce the total score continuums. Figure 3 shows a concave curve for Case 36 (i.e. Outcome 1), a positive convex curve for Case 37 (i.e. Outcome 3) and a negative convex curve for Case 38 (i.e. Outcome 2). For Case 36 the regression equation coefficients generated by the Excel software package are:

$$
Y=-1397.81+890.84 x-132.60 x^{2}
$$

Table 2: Technical Scores, Fee Scores and Total Scores for Competition Nos. 36,37 and 38 using Equation 2 with a 50/50 predetermined weighting

\begin{tabular}{|l|l|l|l|l|l|l|}
\hline Case No. & TM & F $\$ M$ & TSc & FSc & TotSc & Rank \\
\hline & 45.00 & 3.20 & 45.00 & 50.00 & 95.00 & 3 \\
\hline & 46.95 & 3.24 & 46.95 & 49.43 & 96.38 & 1 \\
\hline 36 & 50.00 & 3.50 & 50.00 & 45.71 & 95.71 & 2 \\
\hline & & Mean & 47.32 & 48.38 & & \\
\hline & & SD & 2.52 & 2.33 & & \\
\hline & & SD Ratio & 1.08 & & & \\
\hline & 40.00 & 5.40 & 40.00 & 50.00 & 90.00 & 2 \\
\hline 37 & 42.53 & 6.06 & 42.53 & 44.59 & 87.12 & 3 \\
\hline & 50.00 & 6.50 & 50.00 & 41.54 & 91.54 & 1 \\
\hline & & Mean & 44.18 & 45.38 & & \\
\hline & & SD & 5.20 & 4.29 & & \\
\hline & & SD Ratio & 1.21 & & & \\
\hline & 35.00 & 4.00 & 38.89 & 50.00 & 88.89 & 1 \\
\hline 38 & 38.86 & 6.23 & 43.18 & 32.09 & 75.27 & 3 \\
\hline & 45.00 & 7.00 & 50.00 & 28.57 & 78.57 & 2 \\
\hline & & Mean & 44.02 & 36.89 & & \\
\hline & & SD & 5.60 & 11.49 & & \\
\hline & & SD Ratio & 0.49 & & & \\
\hline
\end{tabular}


Figure 3: Total score continuums for Cases 36, 37 and 38

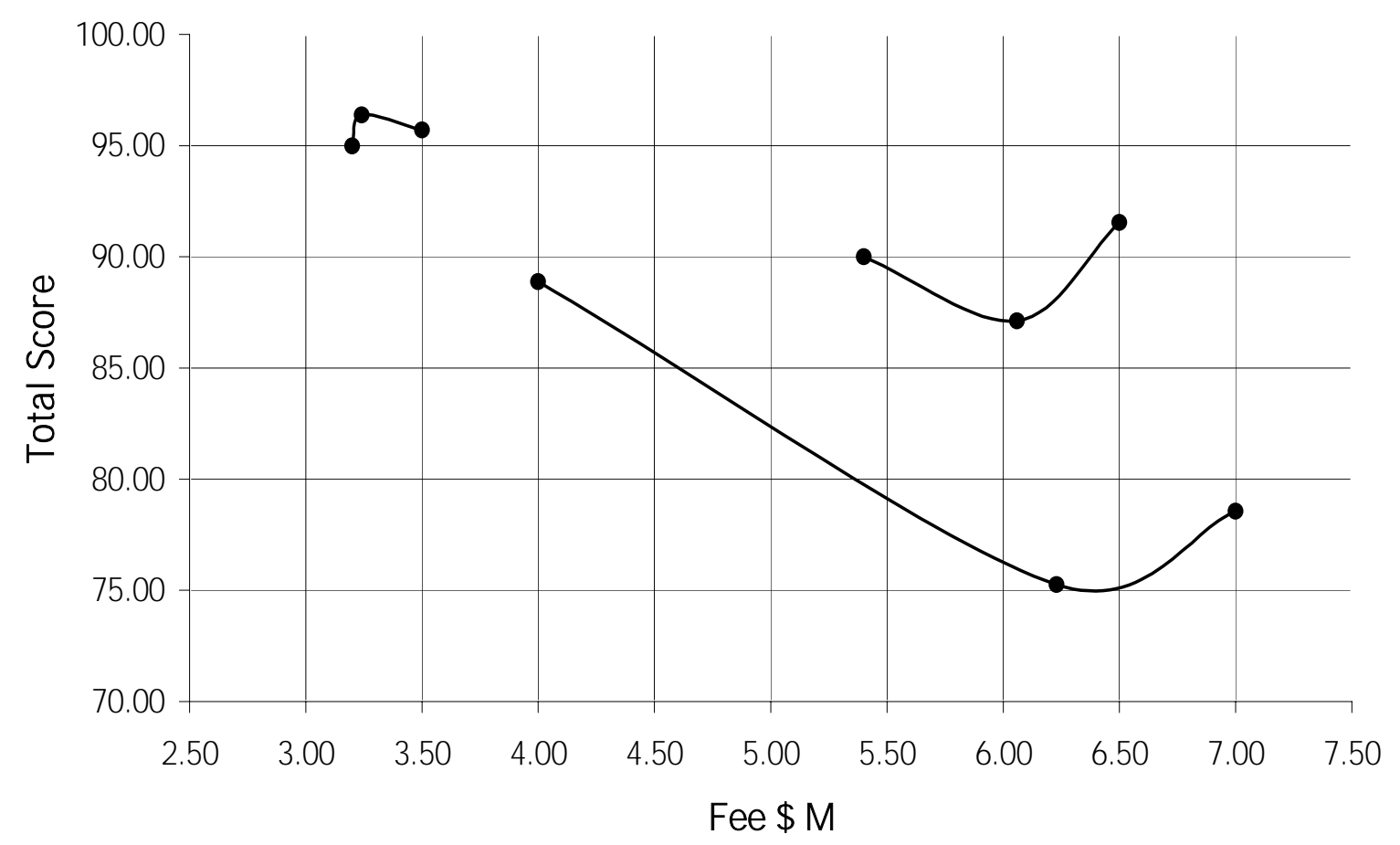

Using differentiation the optimum fee becomes:

$$
\begin{aligned}
Y^{1} & =890.84-265.20 x \\
X & =890.84 / 265.20 \\
X & =3.359
\end{aligned}
$$

With an optimum fee of $\$ 3.359$ million, the optimum total score becomes:

$Y=-1397.81+(890.84 \times 3.359)-\left(132.60 \times 3.359^{2}\right)$

$Y=-1397.81+2992.33-1496.11$

$Y=98.41$

Given an optimum fee of $\$ 3.359$ million and an optimum total score of 98.41 , the corresponding technical score can be found by using Equation 2 i.e.

$98.41=50(q / 50)+50(3.00 / 3.359)$

$98.41=q+44.66$

$q=98.41-44.66$

$q=53.75$

The original technical proposal should be amended to achieve a raw score of 53.75 . The amended technical proposal and a fee of $\$ 3.359$ million should be submitted to the client.
For Cases 37 and 38 the solution is much simpler since the highest score occurs at the either end of the continuum. For Case 37 the consultant should submit a fee of $\$ 6.5$ million and adjust the technical proposal to obtain a raw score of 50.00. For Case 38 the consultant should put in a fee of $\$ 4.00$ million and adjust the technical proposal to obtain a raw score of 35.00 .

\section{FREQUENCY OF THE THREE DIFFERENT OUTCOMES ANDEFFECT OF THE PREDETERMINED WEIGHTINGS}

The three cases illustrate each of the possible outcomes. The same approach was used to analyse all 51 cases. Interestingly Table 3 shows that in only 10 cases did the optimum total score fall in between absolute low fee and absolute high technical score (i.e. Outcome 1), while in 20 cases it aligned with absolute low fee (i.e. Outcome 2) and in 21 cases with absolute high technical score (i.e. Outcome 3). The results show that the optimum fee - technical proposal combination will most likely occur at one end of the consultant's continuum and there is an almost even chance of it occurring either at the low fee or high technical score end of the continuum. 
The reason why there are only 10 cases that produce a result in between absolute low fee and absolute high technical score (i.e. Outcome 1 ) is because of the variability differences between fees and technical score. This can be explained by referring back to the three representative cases. Table 2 shows the respective fee and technical score standard deviations of 2.52 and 2.33 for Case 36. This produces a standard deviation ratio of 1.08 meaning that fee and technical scores are almost equal in terms of variability (see Drew et al. 2002a for adetailed treatment of this aspect). For Case 37 it can be seen that technical scores vary more than fee score meaning that technical score is more dominant in the aggregation and for Case 38 fee score varies more than technical score meaning that fees are more dominant in the aggregation. In other words, Outcome 1 (i.e. in between) will be most likely to occur where the fee/technical score variability is more or less equal. However, where fee score varies more than technical score, Outcome 2 (i.e. absolute low fee) is likely to occur and where technical score varies more than fee score, Outcome 3 (i.e. absolute high technical score) is likely to occur.
The even split of 15 low fee competitions to 15 high technical score competitions for 50/50 and corresponding 5 to 6 for 70/30 indicates that the change in weightings from $70 / 30$ to $50 / 50$ has very little effect on the proportion of competitions that require a low fee or high technical score.

\section{The effect of optimum bidding strategy} on original bidding performance

Tables 4 and 5 show the actual and percentage differences between optimal total scores and original total scores obtained by the consultant for the $70 / 30$ and $50 / 50$ predetermined weightings. For $70 / 30$ predetermined weightings Table 5 shows that the consultant's overall total score increased from 88.08 to 92.19 giving an average improvement of $4.84 \%$. For $50 / 50$ Table 6 shows that the consultant's overall score increased from 82.61 to 88.74 making an average improvement of $7.90 \%$. Tables 5 and 6 also show that the overall improvement range is from $30.80 \%$ to just $0.41 \%$. Interestingly there were eleven competitions whereby the original total score could be improved on by more than $10 \%$. The average improvement of optimal total score on original total score over the 51 cases was $7.07 \%$.

Table 3: Effect of predetermined weightings on optimum bid strategy outcome

\begin{tabular}{|l|l|l|l|l|}
\hline Weightings & $\begin{array}{l}\text { Absolute Low } \\
\text { Fee }\end{array}$ & $\begin{array}{l}\text { Absolute High } \\
\text { Technical Score }\end{array}$ & In-between & Total \\
\hline $50 / 50$ & 15 & 15 & 7 & 37 \\
\hline $70 / 30$ & 5 & 6 & 3 & 14 \\
\hline Total & 20 & 21 & 10 & 51 \\
\hline
\end{tabular}

Table 4: Original total score/ optimum total score comparisons using 70/30 predetermined weightings

\begin{tabular}{|l|l|l|l|l|}
\hline Competition No & $\begin{array}{l}\text { Optimal } \\
\text { Score }\end{array}$ & $\begin{array}{l}\text { Original } \\
\text { Score }\end{array}$ & $\begin{array}{l}\text { Actual } \\
\text { Difference }\end{array}$ & $\begin{array}{l}\text { Percentage } \\
\text { change }\end{array}$ \\
\hline 1 & 88.00 & 86.77 & 1.23 & 1.41 \\
\hline 2 & 88.20 & 80.27 & 7.93 & 9.88 \\
\hline 3 & 88.36 & 87.09 & 1.27 & 1.46 \\
\hline 4 & 85.83 & 78.56 & 7.27 & 9.25 \\
\hline 5 & 88.24 & 81.92 & 6.32 & 7.71 \\
\hline 43 & 95.00 & 85.07 & 9.93 & 11.67 \\
\hline 44 & 94.00 & 87.33 & 6.67 & 7.64 \\
\hline 45 & 95.00 & 93.65 & 1.35 & 1.45 \\
\hline 46 & 93.64 & 88.67 & 4.96 & 5.60 \\
\hline 47 & 95.45 & 94.47 & 0.98 & 1.04 \\
\hline 48 & 95.92 & 95.53 & 0.39 & 0.41 \\
\hline 49 & 95.00 & 92.01 & 2.99 & 3.25 \\
\hline 50 & 93.99 & 92.75 & 1.24 & 1.34 \\
\hline 51 & 94.00 & 88.98 & 5.03 & 5.65 \\
\hline Average & 92.19 & 88.08 & 4.11 & 4.84 \\
\hline
\end{tabular}


Table 5: Original total score/ optimum total score comparisons using 50/50 predetermined weightings

\begin{tabular}{|c|c|c|c|c|}
\hline Competition No & $\begin{array}{l}\text { Optimal } \\
\text { Score }\end{array}$ & $\begin{array}{l}\text { Original } \\
\text { Score }\end{array}$ & $\begin{array}{l}\text { Actual } \\
\text { Difference }\end{array}$ & $\begin{array}{l}\text { Percentage } \\
\text { change }\end{array}$ \\
\hline 6 & 85.63 & 80.03 & 5.60 & 7.00 \\
\hline 7 & 78.69 & 73.39 & 5.30 & 7.22 \\
\hline 8 & 80.25 & 71.49 & 8.76 & 12.26 \\
\hline 9 & 80.00 & 68.54 & 11.46 & 16.72 \\
\hline 10 & 80.19 & 76.44 & 3.75 & 4.90 \\
\hline 11 & 84.68 & 77.56 & 7.11 & 9.17 \\
\hline 12 & 84.87 & 81.63 & 3.24 & 3.97 \\
\hline 13 & 90.83 & 86.76 & 4.07 & 4.70 \\
\hline 14 & 91.55 & 84.74 & 6.81 & 8.04 \\
\hline 15 & 86.84 & 66.39 & 20.45 & 30.80 \\
\hline 16 & 99.74 & 90.58 & 9.16 & 10.12 \\
\hline 17 & 87.50 & 83.50 & 4.00 & 4.80 \\
\hline 18 & 95.65 & 92.14 & 3.51 & 3.81 \\
\hline 19 & 86.96 & 83.50 & 3.46 & 4.15 \\
\hline 20 & 86.96 & 85.26 & 1.70 & 1.99 \\
\hline 21 & 88.64 & 87.82 & 0.82 & 0.94 \\
\hline 22 & 87.56 & 86.30 & 1.27 & 1.47 \\
\hline 23 & 86.96 & 81.66 & 5.29 & 6.48 \\
\hline 24 & 86.96 & 83.51 & 3.44 & 4.12 \\
\hline 25 & 86.96 & 85.11 & 1.85 & 2.17 \\
\hline 26 & 89.47 & 86.04 & 3.43 & 3.99 \\
\hline 27 & 86.96 & 81.87 & 5.09 & 6.21 \\
\hline 28 & 90.80 & 89.28 & 1.52 & 1.71 \\
\hline 29 & 86.96 & 67.30 & 19.66 & 29.21 \\
\hline 30 & 88.46 & 86.66 & 1.81 & 2.08 \\
\hline 31 & 88.89 & 82.23 & 6.66 & 8.10 \\
\hline 32 & 92.94 & 81.97 & 10.97 & 13.38 \\
\hline 33 & 86.96 & 73.24 & 13.71 & 18.72 \\
\hline 34 & 87.50 & 85.57 & 1.93 & 2.25 \\
\hline 35 & 91.82 & 88.92 & 2.89 & 3.25 \\
\hline 36 & 98.41 & 96.44 & 1.97 & 2.05 \\
\hline 37 & 91.54 & 87.12 & 4.42 & 5.07 \\
\hline 38 & 88.89 & 75.27 & 13.62 & 18.09 \\
\hline 39 & 88.89 & 78.18 & 10.71 & 13.70 \\
\hline 40 & 96.43 & 94.98 & 1.45 & 1.53 \\
\hline 41 & 96.43 & 85.97 & 10.46 & 12.17 \\
\hline 42 & 95.00 & 89.20 & 5.80 & 6.50 \\
\hline Average & 88.74 & 82.61 & 6.13 & 7.90 \\
\hline
\end{tabular}

\section{CONCLUSIONS}

Drew et al. (2002b) proposed an optimal two envelope fee bid strategy model using hypothetical examples. 51 bidding attempts, supplied by a Hong Kong quantity surveying consultant, were used in this paper to test the model. It was found that consultants could improve there total score by an average of $7.07 \%$. The difference in total score improvement varies from just $0.41 \%$ to $30.80 \%$. There are eleven competitions where the consultant's original total score could be improved by more than $10 \%$.

It was found that when fee scores vary more than technical scores, fees become the dominant variable. In such cases the optimum strategy is to aim for an absolute low fee-low scored technical proposal combination. Where technical scores vary more than fees, the optimum strategy is to aim for an absolute high technical score-high fee combination. Where the variability of fee 
scores and technical scores are more or less equal, the optimum strategy is to aim somewhere in between these two extremes. The optimum strategy was to aim for an absolute low fee-low scored technical proposal on 21 occasions, absolute high scored technical proposal-high fee on 20 occasions and somewhere between these two extremes on the remaining ten occasions. A key reason for the optimum bidding strategy being at the end of the consultant's total score continuum for the vast majority of competitions is the differences in fee and technical score variability.

A limitation of this model is that the consultant's total score continuum is represented by three points, the minimum number required to produce a quadratic equation. In addition this model is based on the consultant's best estimates of the client's technical score. Suggestions for further research are to improve the model's reliability by (1) including additional combinations of fees and technical scores and measure the effect on the optimum total score and (2) measure the consultant's accuracy of the consultant's estimate of the client's technical score, determine the reasons for the inaccuracy and then attempt to improve the accuracy. The analysis could also be extended by comparing the competing consultant's optimal fee/technical score with those of the successful consultants.

\section{REFERENCES}

Callahan, M.T., Quackenbush, D.G. and Rowings, J.E. (1992) Construction Project Scheduling. McGraw-Hill, New York.

Carr, R. I. (1982) General bidding model, J ournal of the Construction Division. American Society of Civil Engineers, 108, 639-650.

Connaughton, J. (1994) Value by Competition. Construction Industry Research and Information Association, London.

Construction Industry Board (1996) Selecting Consultants for the Team: Balancing Quality and Price. Construction Industry Board, Thomas Telford Publishing, London.

Drew, D.S., Li, H. and Shen, L.Y. (2000) Feedback in competitive fee tendering. Journal of Construction Procurement, 6 (2), 220-230.
Drew, D.S., Ho, L.C.Y. and Skitmore, R.M. (2001) Analysing a consultant's competitiveness in two envelope fee tendering. Construction Management and Economics, 19, 503-510.

Drew, D.S., Tang, S.L.Y. and Lo, H.P. (2002a) Developing a tendering strategy in two envelope fee tendering based on technical score fee variability. Construction Management and Economics, 20, 67-81.

Drew, D.S., Shen L.Y. and Zou, P.X.W. (2002b) Developing an optimal bidding strategy in two envelope fee bidding. Construction Management and Economics (accepted for publication).

Friedman, L. (1956) A competitive bidding strategy. Operations Research, 1 (4), 104112.

Gates, M. (1967) Bidding strategies and probabilities. Journal of the Construction Division, American Society of Civil Engineers, 93, 75-107.

Herbsman, ZJ ., Chen, W.T. and Epstien, W.C. (1995) Time is money: innovative contracting methods in highway construction. ASCE Journal of Construction Engineering and Management, 121 (3), pp.273-281.

Hong Kong Government (1993) Handbook on Selection, Appointment and Administration of Architectural and Associated Consultants. Architectural Services Department, Hong Kong Government.

Hoxley, M. (1998) Value for Money? The Impact of Competitive Fee Tendering on Construction Professional Service Quality. The Royal Institution of Chartered Surveyors, London.

Shen, L.Y., Drew D.S. and Zhang Z.H. (1999) An optimal bid model for price-time biparameter construction contracts. ASCE Journal of Construction Engineering and Management, 125 (3), pp.204-209. 